\title{
Review of Hygroscopic Coating on Aluminum Fin Surface of Air Conditioning Heat Exchanger
}

\author{
Song $\mathrm{He}^{1, * \mathbb{D}}$, Wang Chen ${ }^{1}$, Wansheng Yang ${ }^{2}$ and Xudong Zhao ${ }^{3} \mathbb{C}$ \\ 1 School of Energy and Electromechanical Engineering, Hunan University of Humanities, Science and Technology, \\ Loudi 417000, China; chenwang@huhst.edu.cn \\ 2 School of Civil and Transportation Engineering, Guangdong University of Technology, \\ Guangzhou 510006, China; gdyws@gdut.edu.cn \\ 3 School of Engineering, University of Hull, Hull HU6 7RX, UK; Xudong.Zhao@hull.ac.uk \\ * Correspondence: hnsonghe@huhst.edu.cn; Tel.: +86-(0)-738-837-1136
}

Citation: He, S.; Chen, W.; Yang, W.; Zhao, X. Review of Hygroscopic Coating on Aluminum Fin Surface of Air Conditioning Heat Exchanger. Appl. Sci. 2021, 11, 5193. https:// doi.org/10.3390/app11115193

Academic Editor: Constantinos E. Salmas

Received: 11 May 2021

Accepted: 31 May 2021

Published: 3 June 2021

Publisher's Note: MDPI stays neutral with regard to jurisdictional claims in published maps and institutional affiliations.

Copyright: (c) 2021 by the authors. Licensee MDPI, Basel, Switzerland. This article is an open access article distributed under the terms and conditions of the Creative Commons Attribution (CC BY) license (https:// creativecommons.org/licenses/by/ $4.0 /)$.

\begin{abstract}
Air conditioning energy consumption accounts for most building energy consumption, indoor dehumidification is the main cause of air conditioning energy consumption. Optimize the dehumidification methods of air conditioning systems have great significance to the development of green buildings and people's pursuit of comfort. Improvement of fins on air conditioning heat exchangers is a hot topic of current research and has achieved considerable results in terms of indoor dehumidification and energy saving compared to traditional air conditioners. This paper reviews two kinds of heat exchangers modified by coating, including desiccant-coated heat exchangers and hydrophobic/hydrophilic coated heat exchangers. For desiccant-coated heat exchangers, the preparation methods of advanced desiccant materials and the possibilities of using this material to achieve excellent energy efficiencies were presented, and the operating parameters that affect thermal performance and dehumidification are determined, including airflow temperature, air velocity, inlet air relative humidity, and regeneration temperature. For hydrophobic/hydrophilic coated heat exchangers, different kinds of hybrid hydrophobic-hydrophilic surfaces are highlighted for they are a high water droplet nucleation rate and surface heat transfer efficiency. In addition, the challenges and future works are explained at last. This paper will provide a valuable reference for the follow-up research, which will be helpful for indoor humidity control and reducing the energy consumption of air conditioning.
\end{abstract}

Keywords: hydrophobic/hydrophilic coated heat exchangers; desiccant-coated heat exchangers; dehumidification; energy saving

\section{Introduction}

With the advancement of science and technology, people's lives have improved significantly, and they are pursuing a more comfortable living environment. Temperature, humidity, and air cleanliness are the main parameters to evaluate the indoor air environment. When the moisture of the building exceeds a certain level, it will not only affect people's comfort but also result in the growth of fungus stirring up, not conducive to people's production and life. At present, more than $90 \%$ of air dehumidification systems are based on condensing moisture by the air conditioner to dehumidify the air [1]. To meet the indoor humidity comfort, the conventional air conditioning system generally maintained the evaporative cooling temperature much lower than the air dew point temperature. It is necessary for the air after cooling and dehumidification to go through a reheating process to ensure indoor thermal comfort [2]. There is a serious waste of energy and cannot meet the development requirements of green buildings. It was reported that air conditioning system accounts for over $50 \%$ of the building energy consumed in developed countries [3]. Air conditioning load generally includes latent heat load and sensible heat load, and the former is usually more than twice the latter [4]. Therefore, the improvement 
of air conditioning system dehumidification performance has great potential for building energy conservation.

Aluminum fins are widely used in air conditioner heat exchangers, due to their high thermal conductivity, low cost, and wide source of raw materials. However, there are some drawbacks about the ordinary aluminum fins: Weak adsorption to water molecules limits dehumidification capacity; during the refrigeration process, water molecules condense into droplets adhering to the surface of the fins, increasing the wind resistance of the heat exchanger, resulting in a decrease of the heat transfer efficiency, and hindering the continuous condensation of water molecules. To solve the above problems, researchers have proposed several novel dehumidification methods, which were divided into two categories: (1) Coating desiccants on the fins, it should be mentioned that the porous adsorption desiccants are mainly considered here when the process air flows over the fin side of the heat exchanger, the water molecules will be absorbed into the desiccant pores. Using a two-unit heat exchanger system, one unit is saturated and then enters the regenerative state, switching to another unit to continuously cool and dehumidify [5]. This method can dehumidify indoor air without lowering the evaporative cooling temperature below the air dew point temperature, which is of great significance in energy-saving and indoor comfort. (2) Changing the physical or chemical properties of the heat exchanger fin surface to form wettability surfaces, including hydrophobic surfaces, hydrophilic surfaces, and hybrid hydrophobic-hydrophilic surfaces [6]. This method reduces the evaporative cooling temperature to the air dew point temperature and dehumidifies by condensation. With the same amount of dehumidification, the evaporative cooling temperature of the heat exchanger with wettability aluminum fins can be much higher than that of conventional aluminum fins, with no need for air preheating.

In this paper, a comprehensive review of the key developments in the field of desiccants coating and hydrophobic/hydrophilic coating on the surface of aluminum fins in air conditioning heat exchangers must be presented, respectively. Based on current studies, the challenges of using these approaches and future work will be further analyzed. Other review articles exist about coating heat exchangers to control building humidity $[4,7,8]$, but usually introduced a single type of coating dehumidification method, without combining the desiccants coating and the hydrophobic/hydrophilic coating. The purpose of this review: (1) Summarized the existing research achievement, the characteristics of the two dehumidification methods are analyzed, which will provide a reference for the follow-up researchers; (2) combined with porous adsorption desiccants coating dehumidification and surface condensation hydrophobic/hydrophilic coating dehumidification, a novel coating dehumidification method with both adsorption and condensation functions could be considered; (3) proposed dehumidification research potential in the field of air conditioning and the significance of building energy conservation. At present, there has been much research on the performance improvement of heat exchangers $[9,10]$. Huang et al. [11] structurally studied the influence of the ratio of the length of the heat exchanger to the hydraulic diameter on the heat transfer coefficient. Liang et al. [12] optimized the structural parameters of the heat exchanger. Ganesan et al. [13] reviewed the heat transfer performance of hydrophobic fin and superhydrophobic fin in the heat exchanger. Capri et al. [14] reviewed some major developments in adsorbent coating technology to apply adsorption heat pumps. The main difference between this review and others is that desiccant-coated heat exchangers and hydrophobic/hydrophilic coated heat exchangers are put together for the first time for comparative analysis, their advantages and disadvantages are introduced in detail, and their application status and prospects in the field of air conditioning are analyzed pertinently.

\section{Desiccant-Coated Heat Exchangers}

Many kinds of research have proven that separating to control indoor sensible and latent load has the potential to significantly increase the energy efficiency of the conventional air conditioning system [15-18]. Desiccant is widely used to remove latent load in 
the air $[19,20]$. According to the principle of mesoporous adsorption [21], when the humid air is in direct contact with the dry desiccant, the water molecules will be adsorbed into the mesoporous of the desiccant to achieve the purpose of dehumidifying the air. The desiccant cannot dry the humid air indefinitely, and the moisture absorption rate decreases as the moisture content of the desiccant increases. When the desiccant reaches the critical point of moisture absorption, the dehumidification will be stopped. To continue the operation, removing the water molecules in the desiccant is essential; it is called the regeneration process, which can be carried out by adopting solar energy and low-grade energy.

Desiccant-coated heat exchangers (DCHE) were fabricated by directly coating desiccant material to the outer surface of the conventional fin tube heat exchanger, shown in Figure 1 [22]. When the air conditioning cooling dehumidification mode is turned on, the humid air would flow through the heat exchanger and be in direct contact with the desiccant to remove the latent load; at the same time, a cooling fluid would pass through the tubes to handle sensible load [23,24]. It will provide hot water to the DCHE after the desiccant reaches the adsorption saturation point, and the water will be released in the desiccant to realize the regeneration of the desiccant. The recent advances of DCHE will be explained in the following aspects: Desiccant materials; factors affecting the performance of DCHE, and applications in air conditioning systems.

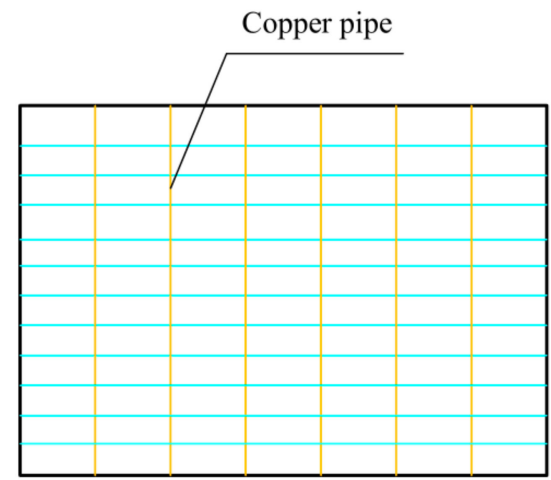

(a)

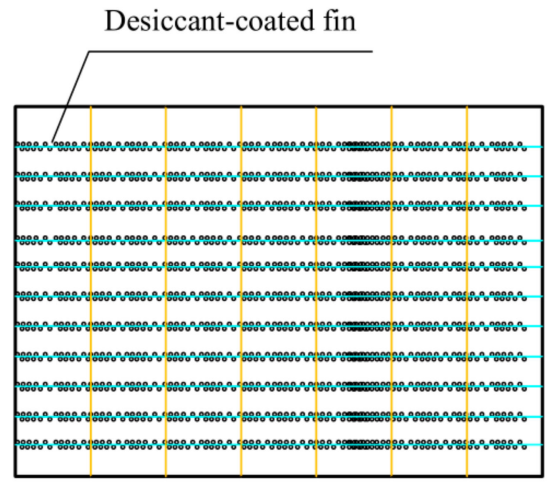

(b)

Figure 1. Fin tube heat exchanger: (a) Without desiccant coating; (b) with desiccant coating [22].

\subsection{Desiccant Materials}

The material of the desiccant is a decisive factor that affects the performance of DCHE. Finding the optimum desiccant suitable for DCHE is a hot research topic at present [25]. Profiting off high sorption capacity and low regeneration temperature desiccant materials was the key to developing coated heat exchangers [26,27]. At first, the desiccant material should have a large saturated adsorption capacity and be easy to reactivate [28]. Besides, regeneration is the most energy consumed in the whole cycle of desiccant. Low regeneration temperature can effectively utilize low-grade energy and renewable energy to improve the efficiency of the DCHE system.

The porous physical desiccant of silica gel has the advantages of high porosity, low cost, and stable adsorption performance; the currently studied DCHE system mainly uses silica gel as the coating desiccant material [29,30]. Bongs et al. [31] constructed an open dehumidification cycle using a silica gel coated heat exchanger, and the results showed that the dehumidification capacity was $46 \%$ higher than that of the traditional device. Ge et al. [32] conducted an experimental comparison between a silicone-coated finned tube heat exchanger and a polymer-coated finned tube heat exchanger, and the results showed that the effective dehumidification time of silicone-coated DCHE was longer, and the average dehumidification capacity was stronger. However, it was reported that when the partial pressure of water vapor is low, the adsorption capacity of silica gel decreases rapidly with the increase of temperature $[33,34]$. 
The pursuit of advanced materials, improving traditional desiccant materials is the main way to prepare superior water-absorbing desiccant materials, for example, immerse hygroscopic salts, such as $\mathrm{LiCl}$ and $\mathrm{CaCl}_{2}$, in conventional desiccants [35,36]. It was proposed that, compared with single silica gel, composite desiccant has higher dehumidification capacity and lower regeneration temperature [37-40]. And composite silica gels not only are more hygroscopic than pure silica gels, but also can enhance thermal conductivity and dynamic sorption properties [41,42]. Hu et al. [43] prepared a novel composite desiccant material by let silica gel acts as a host matrix and inorganic salt like $\mathrm{LiCl}$ is impregnated into its pores. Through experimental testing, they found that DCHE based on composite desiccant materials has higher dehumidification capacity, especially at lower relative humidity. Zheng et al. [29] found that the dehumidification capacity of composite $\mathrm{LiCl}$ and silica gel was $25-45 \%$ higher than that of pure silica gel. Gordeeva et al. [44] proposed that increasing the $\mathrm{LiCl}$ fraction in the binary salt will increase the water adsorption capacity. Ge et al. [45] found that potassium formate and silica gel coated heat exchangers have $20 \%$ higher dehumidification capacity and 50\% higher total cooling capacity than single silica gel coated heat exchangers. Jagirdar et al. [46] found that the finned tube heat exchanger coated with silica gel-supported lithium chloride desiccant can save up to $31 \%$ of energy compared with conventional air conditioning heat exchangers by establishing a mathematical model. Andres et al. [47] prepared new composite desiccant materials for coated heat exchangers, and the experimental testing results show that the dehumidification capacity of silica gel and sodium acetate coated heat exchanger is 30\% higher than the single silica gel coated heat exchanger. Zheng et al. [48] prepared sodium alginate and silica gel composite desiccant, which has twice the water absorption of silica gel, and its dehumidification capacity is $34 \%$ to $60 \%$ higher than that of silica gel coated heat exchangers. In addition, Entezari et al. [49] modified sodium alginate with $\mathrm{LiCl}$ and $\mathrm{CaCl}_{2}$ to obtain a binary polymer salt and compounded it with carbon nanotubes to prepare a composite desiccant, and each gram of this desiccant can absorb about $5.6 \mathrm{~g}$ of water.

However, there are few studies on the influence of impregnated salts molar ratios on sorption performance. Akram et al. [26] found that adding $\mathrm{LiCl}$ to $\mathrm{LiBr}$ can reduce the adsorption capacity by $12.7 \%$, while adding a small amount of $\mathrm{LiBr}$ to $\mathrm{LiCl}$ composites can increase the adsorption capacity by $5.5 \%$. Therefore, the optimum ratio of impregnation hygroscopic salts needs to be further studied.

\subsection{Factors Affecting the Performance of DCHE}

To improve the dehumidification performance of the DCHE system, the factors affecting the operation of the system are discussed, including airflow temperature, air velocity, cooling water temperature, and inlet air humidity content.

Ge et al. [50] found that reducing the cooling water temperature can improve the performance of the system; in addition, the performance of the system increases with the increase of the inlet air temperature and relative humidity. Tomohiro et al. [51] proposed that adsorption and desorption velocities increase with the increase of air velocity, but air velocity has little effect on the equivalent diffusion coefficient of water molecules in the desiccant layer. Sun et al. [52] used the Taguchi method to rank the influencing factors of the heat and mass transfer performance of the DCHE system. For the influencing factors of heat transfer coefficient and moisture transfer, the order was wind speed and water temperature. Chai et al. [53] represented that the main factors affecting the proportion of desiccant dehumidification are the cycle time and airflow rate. When the desiccant dehumidification ratio is close to $50 \%$, the performance of the system is the best.

It could be analyzed from the above that reducing the temperature of cold water, increasing the relative humidity and temperature of the airflow, and increasing the air velocity can improve the dehumidification performance of the DCHE system. It should be mentioned that there will be an optimal critical value of the air velocity, greater than this value will take away the water molecules in the desiccant coating, thereby reducing the dehumidification performance of the DCHE system. 


\subsection{Applications in Air Conditioning Systems}

The desiccant-coated heat exchanger has received great attention because it can reduce the latent heat load in the room by absorbing water molecules, and then regenerate desiccants by using renewable energy or low-grade energy, which effectively reduces air conditioning energy consumption.

Ge et al. [54] integrated a regenerative evaporative cooler, and a desiccation coated heat exchanger, a self-cooling solid dryer cooling system was developed, as shown in Figure 2. The system consists of four groups of working fluids (regeneration air, process air, heating water, cooling water) and three main components (cross-flow falling film evaporative cooler, sensible heat exchanger, desiccant-coated heat exchanger). It operates and switches between dehumidification mode and regeneration mode. The desiccantcoated heat exchanger in the dehumidification process is cooled by the chilled water produced by the regenerative evaporative cooler. In addition, the coated desiccant material is regenerated by hot water heated by low-grade thermal energy. Reprinted with permission from ref. [54]. Copyright 2021 Copyright Clearance Center Elsevier.

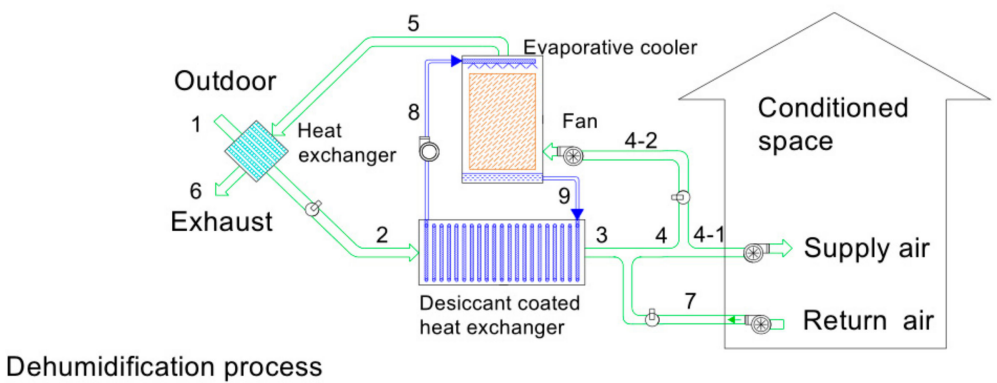

Switch

Regeneration process

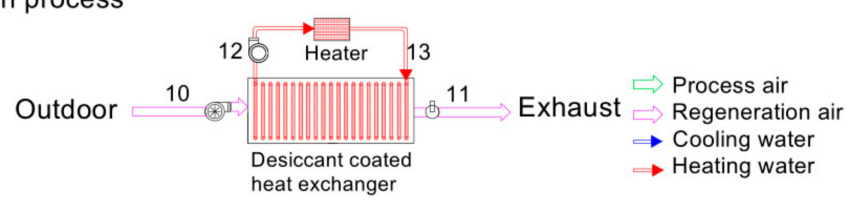

Figure 2. Schematic of self-cooled desiccant-coated heat exchanger cooling system [54].

Turkan et al. [55] proposed a DCHE cooling system driven by solar energy, as shown in Figure 3. The system consists of a desiccant-coated heat exchanger, a solar collector heating system, and an indirect evaporative cooling system. By controlling the valve, the switch can change the cold water, and hot water flows through the heat exchanger, to control the heat exchanger dehumidification and regeneration. Kumar et al. [56] found that for air conditioning systems with silicone coated heat exchangers driven by evacuated tube solar water heaters, pre-cooling can achieve a better dehumidification rate, and it is beneficial to cooling capacity and COPth after the dehumidification process. Reprinted with permission from ref. [55]. Copyright 2021 Copyright Clearance Center Elsevier.

To compare the heat and mass transfer characteristics of the conventional heat exchanger and desiccant-coated heat exchanger, Sun et al. [57] found that the heat transfer capacity of DCHE was reduced by $30 \%$, pressure drop was increased by $60 \%$ (based on the designed experimental testing). This was because of the heat resistance of the desiccant coating. Besides, without changing other structural parameters, doubling the depth of fins increases the average moisture removal by $40 \%$ and COPth by $10 \%$. In order to study the performance of desiccant-coated heat exchanger air conditioning system in winter, Ge et al. [58] built a test bench, and the experimental principle is shown in Figure 4; they found that higher ambient air humidity will lead to an increase in the humidity ratio of the incoming indoor air, the temperature of the ambient air has little effect on the incoming 
indoor air, and choosing the appropriate regeneration temperature and switching time, the

DCHE air-conditioning system can be used for winter operation.

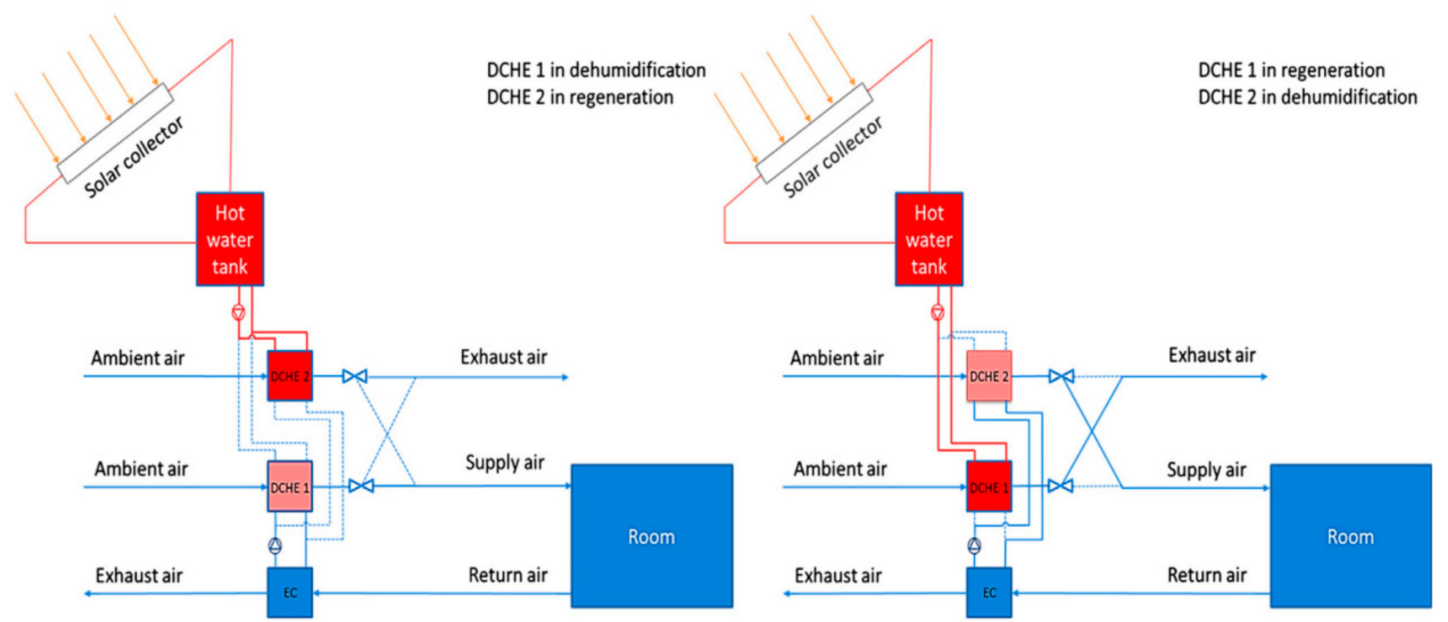

Figure 3. Schematic of the solar-driven desiccant-coated heat exchanger cooling system [55].

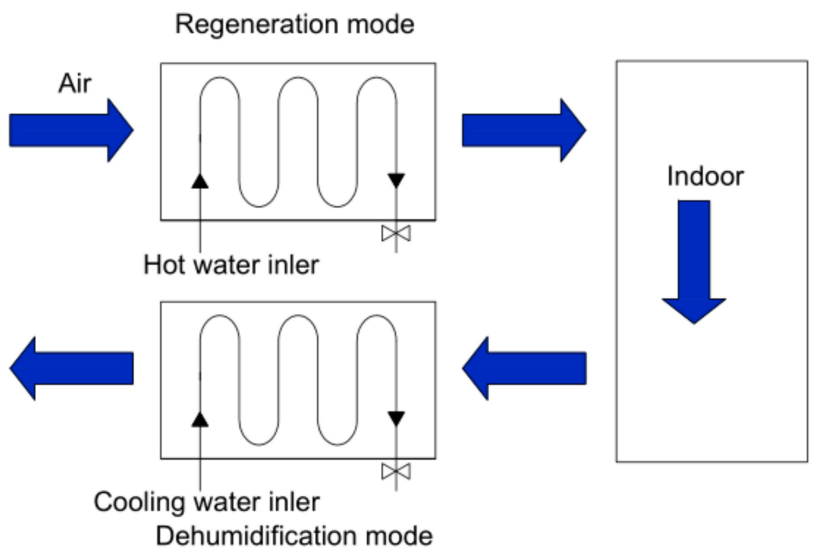

Figure 4. Schematic diagram explaining DCHE air conditioners in winter [58].

\section{Hydrophobic/Hydrophilic Coated Heat Exchangers}

During the operation of the fin-tube heat exchanger, when the surface temperature of the fin is lower than the dew point temperature of the inlet air, condensation phenomena will appear on the surface of the fin [59]. For conventional fin-tube heat exchangers, condensed water adheres to the surface of the fin in the form of water droplets, increasing the pressure drop of the air-side core, provides a site for biological activity, creates the possibility of corrosion, and reduces the air-side heat transfer rate. Furthermore, they have low dehumidification capacity, the evaporator temperature will be reduced by increasing the energy consumption of the air conditioner to meet the comfort requirements of the indoor humidity [60]. To solve the above problems, the condensing surface with both a high nucleation rate and efficient droplet departure has been proposed [61]. At present, the most attractive feature is that hydrophilicity enhances the nucleation process, which requires a large non-condensable gas content and a small degree of subcooling. However, the condensation water film on the hydrophilic surface will impede the heat exchange between the fins and the air and reduce the heat exchange efficiency of the air conditioner. It was reported that the hydrophobic surface could promote the droplets to roll away easily on the condensation surface, and the improved mobility of droplets was demonstrated to successfully enhance the heat exchange characteristics of the air conditioning heat exchanger [62-64]. Therefore, various methods of fabricating hybrid hydrophobichydrophilic surfaces have been proposed, which regions are having hydrophilic behavior 
(contact angle $<90^{\circ}$ ) and regions having hydrophobic behavior (contact angle $>90^{\circ}$ ). Water is harvested on hydrophilic regions; after reaching a critical value, the water droplets will fall off the surface. And hydrophobic regions are used to transport the tiny water droplets and exchange heat between the fins and the air. It could promote the condensed droplets removed from the surface before coalescing into a film, and the nucleation rate and heat exchange efficiency are successfully improved $[65,66]$.

\subsection{State of Surface Wettability}

The surface wettability was described by Thomas Young, as shown in Figure 5, the well-known equation can be written as [67]:

$$
\gamma_{\mathrm{SV}}=\gamma_{\mathrm{SL}}+\gamma_{\mathrm{LV}} \cos \theta_{0}
$$

where $\theta_{0}$ is the contact angle; $\gamma_{\mathrm{SL}}, \gamma_{\mathrm{SV}}$, and $\gamma_{\mathrm{LV}}$ represents the solid-liquid, solid-vapor, and liquid-vapor interfacial tensions, respectively.

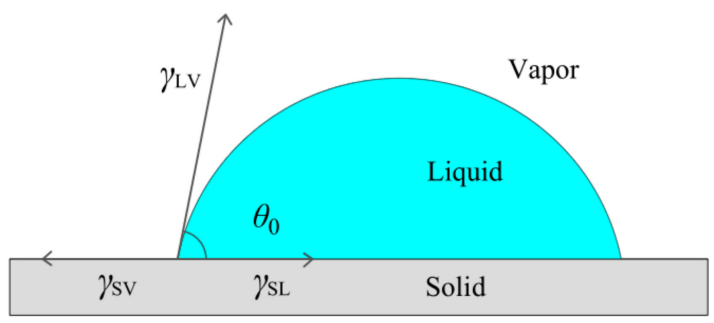

Figure 5. Equilibrium of interfacial tensions of a droplet on a flat surface [63].

However, the Young equation is an idealized model that only suitable for ideally smooth solid surfaces. For a rough surface, the state of the droplets in contact with the surface will be very different. Two wetting states of Wenzel and Cassie-Baxter are defined (Figure 6): The Wenzel model [68] assumes that the liquid wets the whole rough substrate, while the Cassie-Baxter model [69] assumes that because the air in the micro-structure surface is trapped, part of the rough substrate will be wetted by the droplets.

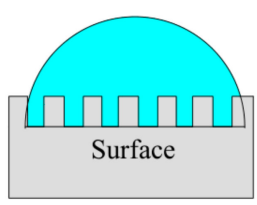

a

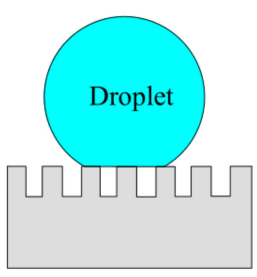

b

Gassie-Baxter model

Figure 6. Wenzel and Cassie-Baxter model [65].

Wenzel proposed the relationship between the surface roughness and the static contact angle of droplets, shown in Equation (2).

$$
\cos \theta_{\mathrm{w}}=r \times \cos \theta_{0}
$$

where $\theta_{\mathrm{w}}$ is the apparent contact angle; $r$ is the roughness ratio. It can be seen from the equation that the decisive factors affecting the apparent contact angle are the surface morphology $r$ and the surface chemical composition $\theta_{0}$.

For the surface with high roughness, the absolute value of $r \times \cos \theta_{0}$ may be greater than 1. Therefore, Cassie and Baxter introduced another formula based on the Wenzel model, shown in Equation (3).

$$
\cos \theta_{\mathrm{c}}=-1+\left(1+r_{\mathrm{f}} \times \cos \theta_{0}\right) \times f
$$


where $\theta_{\mathrm{c}}$ is the apparent contact angle; $f$ represents the fraction of solid surface area wet by the liquid; $r_{\mathrm{f}}$ is the roughness ratio of the wet surface area.

\subsection{Kinds of Surface Wettability}

As were demonstrated in the previous studies [70], a simple hydrophobic or hydrophilic surface could be obtained by the surface substrate's chemical modification or topographical modification. High droplet nucleation rates have been reported on hydrophilic surfaces, and the hydrophobic surface revealed a better heat transfer performance [61]. And in the air condition heat exchanger, the surface of the condensing fins is required to have both efficient droplet mobility and high nucleation ability to enhance dehumidification capacity. Therefore, the hybrid surface has been introduced, and the different patterned model would be discussed as follows:

Cactus model: Inspired by cactus, which captures water molecules by the hydrophilic needles and is transported by the hydrophobic spine. Bikash et al. [71] forced an array of hydrophilic needles through a robust superhydrophobic polymer film to prepare a superhydrophobic-hydrophilic surface (Figure 7). Due to the difference in temperature and wettability, condensation occurs preferentially on the needle surface. As the droplet grows, the droplet on the needle maintains the Cassie state and does not wet the superhydrophobic surface below. They observed that the water condensation rates of the hybrid surface were twice that of a single superhydrophobic surface and four times that of a flat copper surface. Ju et al. [72] prepared a cactus model surface by combining mechanical perforating and template replica technology; the condensation water droplets grow on the hydrophilic needle and then moving down onto the hydrophobic. Their design opens up a new avenue to adsorb water molecules efficiently and may be potentially useful for indoor dehumidification field. Hu et al. [73] fabricated the hybrid surfaces of hydrophilicsuperhydrophobic (HS). And the experimental tests have been carried out, and the results show that when there is a large amount of non-condensable gas, the surface has high condensation heat transfer performance, but it does not show excellent performance for pure steam condensation. In addition, they concluded that relative humidity is one of the main factors affecting the condensation heat transfer coefficient.

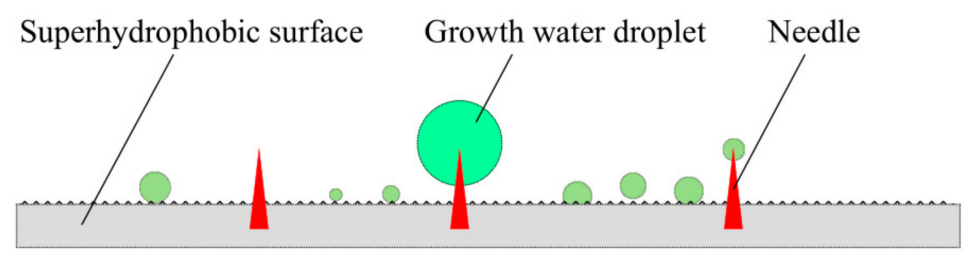

Figure 7. Condensation on a hybrid surface [71].

Grass model: Inspired by grass, which captures water molecules by the hydrophilic leaves and is transported by the hydrophobic stems. Mahapatra et al. [74] laid super hydrophilic tracks (filmwise condensation domain) on a hydrophilic surface (Figure 8). This design facilitates the timely drainage of capillary-driven condensate, reduces the residence time of the condensate droplets on the hydrophilic surface, increases the heat exchange area where the air is in direct contact with the surface, and enhances the heat transfer coefficient of the surface. And the experimental results show that this composite metal surface can increase the heat transfer performance by $30 \%$. 


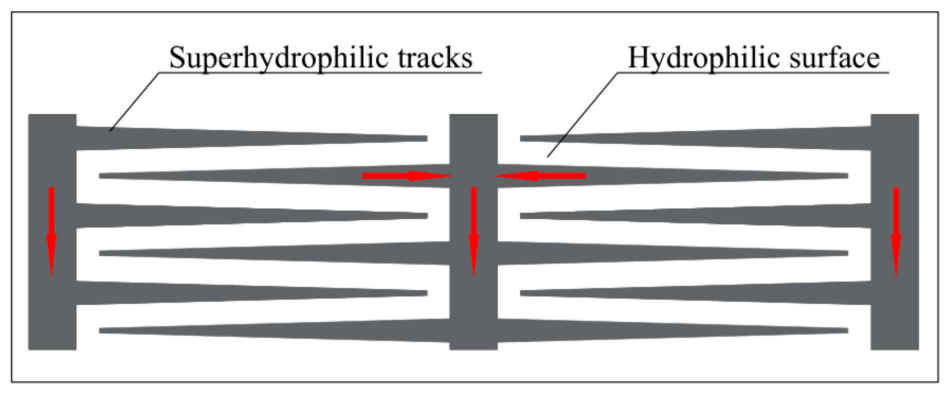

Figure 8. Periodically patterned samples for condensation experiments [74].

Ghosh et al. [75] laid the super-hydrophilic tracks of the bio-inspired wettability patterned on the hydrophilic surface. When the droplets generated on the hydrophilic surface grow up, they will be sucked away by the super-hydrophilic tracks, forming a water film. Driven by the capillary force, the condensate can be drained in time on the superhydrophilic tracks, which effectively enhances the condensation heat transfer performance of the surface. They demonstrated that in a non-condensable vapor environment, the performance of the patterned surface was improved by $19 \%$ compared with the normal hydrophilic surface. Derby et al. [76] studied the flow and condensation heat transfer of pure steam on different wettability surfaces, including hydrophobic copper, hydrophilic copper, and two surfaces with a combination of hydrophilic and hydrophobic patterns (Figure 9). They found that the condensation heat transfer coefficient on the surface of the hybrid pattern is an order of magnitude higher than that of a single hydrophilic or hydrophobic surface.
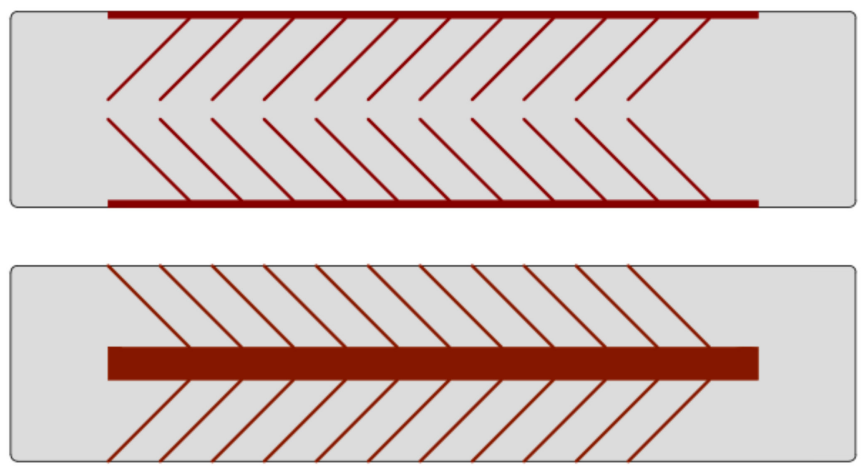

Hydrophilic: rufous; hydrophobic: gray

Figure 9. Schematic detailing hydrophobic/hydrophilic patterned surfaces [76].

Alwazzan et al. [77] prepared hybrid-patterned surfaces, and compared them with a single hydrophilic surface of filmwise condensation, and they showed a significant enhancement in heat flux and condensation heat transfer coefficient. They reported that the surface with $\beta$ and $\alpha$ zones are $0.6 \mathrm{~mm}$ and $0.3 \mathrm{~mm}$, respectively, which have improved heat transfer performance by $480 \%$ and $180 \%$, respectively, compared with the filmwise and dropwise condensation surface. The $\beta$-regions are where the droplets nucleate. After the droplets grow up, they will be absorbed by the $\alpha$-regions. Under the action of gravity, the condensed water can be quickly drained along the $\alpha$-regions (Figure 10). 


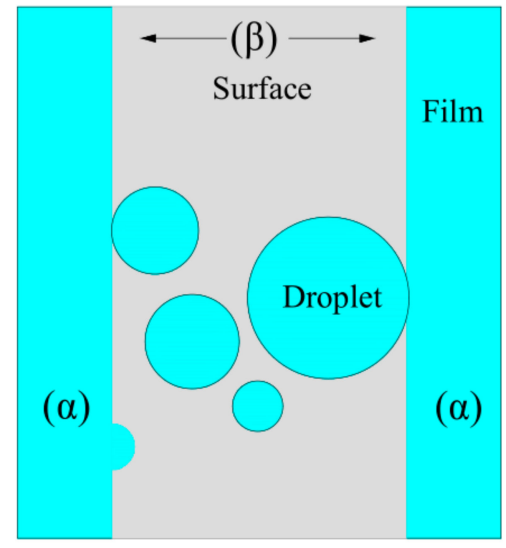

Figure 10. Concept of droplet migration mechanism between two different wettability regions [77].

Namib desert beetle model: Inspired by the Namib desert beetle, which captures water molecules by wax-free hydrophilic bumps and is transported by the waxy hydrophobic surround. Yin et al. [78] deposited the polytetrafluoroethylene nanoparticles prepared by femtosecond laser onto the superhydrophobic copper mesh, and the copper mesh was coated on the hydrophilic copper sheet to prepare the hybrid superhydrophobichydrophilic surface, as shown in Figure 11, and soaked in $1 \mathrm{M} \mathrm{NaOH}, 1 \mathrm{M} \mathrm{HCl}$, and $10 \mathrm{wt} \%$ $\mathrm{NaCl}$ solution for $2 \mathrm{~h}$, respectively, the surface has excellent corrosion resistance.

Copper mesh Nanoparticles deposited

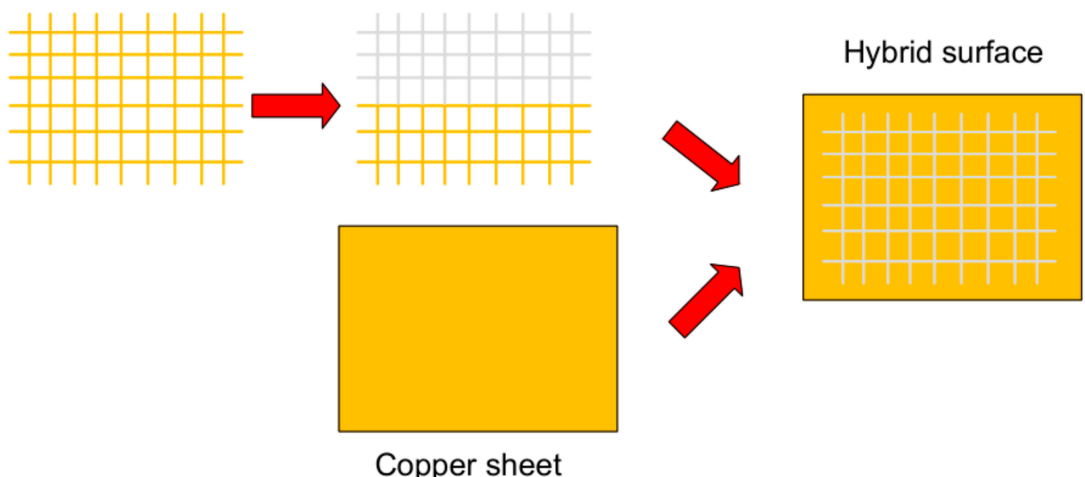

Figure 11. The preparation procedure for the hybrid superhydrophobic-hydrophilic surfaces [78].

Cao et al. [79] prepared a hydrophobic/hydrophilic cooperative Janus system (Figure 12), which could reduce the re-evaporation rate of harvested water molecules, and a thinner collection surface boundary layer helps improve absorption efficiency.

Janus system

Hydrophobic copper mesh

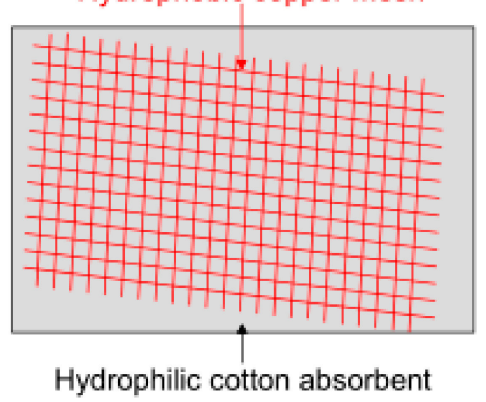

Figure 12. Structure schematic diagram of Janus System [79]. 
Li et al. [80] proposed a simple method to create a superhydrophilic micropattern on a superhydrophobic surface by printing a lipid ethanol solution onto the porous superhydrophobic surface. Garrod et al. [81] prepared various hydrophilic and hydrophobic patterned surfaces by using a simple two-step plasmachemical method. And it was found that the surface is suitable for water microcondensation. The water droplets formed on the hydrophobic surface will flow to the hydrophilic region, and combined with droplets already present on the hydrophilic region, then continue to grow on the surface, and drop down after reaching the critical point of gravity. Hou et al. [82] mimicked the beetle's back to prepare a hybrid surface, which compared with the single hydrophobic surface, the heat transfer coefficient is increased by $63 \%$. Zhai et al. [83] used poly-water/2-propanol solution to deposit a series of hydrophilic spots on the superhydrophobic surface to form a mixed wettability structure. Zhang et al. [84] used inkjet printing technology to prepare superhydrophilic micropatterns on superhydrophobic surfaces. Compared with uniform superhydrophobic and superhydrophilic surfaces, the water collection efficiency was improved.

It could be concluded from the above research that the hybrid superhydrophobichydrophilic surface has excellent dehumidification and heat transfer performance, but it is a microscopic structure, the preparation technology is difficult, and the preparation conditions are demanding. Most of the research still stays in the laboratory stage and cannot be used in large-scale production on the market. Future development needs to reduce the technical difficulty of generating high-performance wettability surfaces, low production costs, and meet the market demand for large-scale production.

\subsection{Applications in Air Conditioning Systems}

Under the operating conditions of air conditioners, part of the water molecules in the moist air will condense to the fin surface, due to the fin surface temperature being lower than the air dew point temperature [85]. Different condensation modes will affect the heat and mass transfer performance of heat exchangers and other performance parameters. Many researchers have done a lot of research on the effects of treated fins on air conditioning heat exchangers. Ma et al. [86] studied the effects of hydrophilic coating on air-side performance and found that the flow state of condensed water directly affects the influence of the hydrophilic coating on the heat transfer performance of the surface. When a large amount of condensed water flows, the hydrophilic coating can improve the heat transfer performance, and when a small number of condensed water forms on the surface of fins, the hydrophilic coating will reduce the heat transfer performance.

Yang et al. [87] studied the condensation properties of hydrophilic, superhydrophilic, hydrophobic, and hydrophobic-hydrophilic hybrid pattern surfaces, respectively. They found that the heat transfer coefficient of the hydrophilic surface was lower than that of the hydrophobic surface, and the superhydrophilic surface was the worst because of the filmwise condensation of water molecules on the surface. Wang et al. [88] proposed that under completely dry surface conditions, the influence of the hydrophilic coating on the thermal-hydraulic performance was negligible, and the pressure drops were approximately $15-40 \%$ lower than those without coating. Wang et al. [89] examined the influence of environmental parameters on the performance of both hydrophilic coated and uncoated surfaces of the fin-tube heat exchangers in wet conditions, finding the effect of inlet relative humidity on the heat transfer performance was small. They also found that because of the condensate flow pattern along the fin surface, the effect of inlet relative humidity has a pronounced effect on pressure drops for un-coated surfaces. Kim et al. [90] applied hydrophobic, hydrophilic, and hydrophobic-hydrophilic hybrid pattern coatings to the fins of the heat exchanger, respectively. Through experimental testing, they found that the hydrophilic unit had a lower air-side pressure drop than the others. 


\section{Challenges and Future Works}

Reducing air conditioning energy consumption and improving indoor comfort are common goals of air conditioner researchers. The previous research has achieved fruitful results and made outstanding contributions to green building. Meanwhile, some obstacles need further research and improvement.

\subsection{For Desiccant-Coated Heat Exchangers}

DCHE has shown great potential in air condition system applications. Combining with mentioned above, there are some potential areas for consideration.

1. After the addition of the hygroscopic salts, the adsorption capacity of the conventional desiccants has been significantly improved. However, their negative consequences, such as corrosion and deliquescence, require further research.

2. How to reduce the pressure drop and enhance the mass and heat transfer of the DCHE, and reduce the desiccants regeneration temperature need to be developed.

3. In the air conditioning system, the dehumidification and regeneration system is complex, difficult to control, and large, which requires a more competitive design.

\subsection{For Hydrophobic/Hydrophilic Coated Heat Exchangers}

According to the previous sections, high water droplet nucleation rate and surface heat transfer efficiency are two intrinsic characteristics of hydrophobic/hydrophobic surfaces. However, some shortcomings need to be overcome.

1. Hybrid hydrophobic-hydrophilic coated surfaces are complex, which are difficult or expensive to fabricate; it is necessary to find a simple preparation method suitable for industrial production.

2. Most of these hydrophobic/hydrophilic coating surfaces have poor mechanical durability and often fail after dust clogging and metal oxidative corrosion.

The types of aluminum fins currently used in air conditioners and their advantages and disadvantages are shown in Table 1.

Table 1. Types of aluminum fins and their characteristics.

\begin{tabular}{|c|c|c|}
\hline Aluminum Sheet Types & Advantages & Disadvantages \\
\hline Conventional & $\begin{array}{c}\text { Simple production and low initial } \\
\text { investment }\end{array}$ & $\begin{array}{c}\text { Weak dehumidification capacity, low heat } \\
\text { transfer coefficient }\end{array}$ \\
\hline Desiccant-coated & $\begin{array}{l}\text { Strong dehumidification capacity, } \\
\text { recyclable low-grade energy }\end{array}$ & $\begin{array}{l}\text { High initial investment and difficult } \\
\text { system control }\end{array}$ \\
\hline Hydrophobic coated & High heat transfer coefficient & Weak dehumidification capacity \\
\hline Hydrophilic coated & Strong dehumidification ability & Low heat transfer coefficient \\
\hline Hydrophobic/hydrophilic coated & $\begin{array}{l}\text { High water droplet nucleation rate and } \\
\text { surface heat transfer efficiency }\end{array}$ & $\begin{array}{l}\text { Expensive to fabricate and poor } \\
\text { mechanical durability }\end{array}$ \\
\hline
\end{tabular}

\section{Conclusions}

Conventional air conditioning has weak dehumidification capacity and high energy consumption, cannot meet people's requirements. In recent years, substantial research has been focused on improving the dehumidification capacity of air conditioners by optimizing the fins of air conditioner heat exchangers to achieve energy-saving and comfortable effects. This paper reviews two kinds of heat exchangers modified by coating, including desiccant-coated heat exchangers and hydrophobic/hydrophilic coated heat exchangers.

Desiccant-coated heat exchangers have displayed the potential to provide superior dehumidification capacity. Different materials have been coated on desiccant-coated heat exchangers to achieve an efficient performance. Some latest studies show that the composite desiccants made by mixing $\mathrm{LiCl}$ salt with the pure silica gel have performed better than their pure counterparts. Besides, the influencing factors have also been discussed, such as 
air velocity increased, the adsorption and desorption speeds also increased. Hydrophobic/hydrophilic coated heat exchangers are also widely used in air conditioning dehumidification. Moreover, many experiments have shown that hybrid hydrophobic-hydrophilic coated surfaces have better dehumidification performance than single hydrophobic or hydrophilic aluminum surfaces.

Lastly, although desiccant-coated heat exchangers and hydrophobic/hydrophilic coated heat exchangers have extraordinary potential in indoor dehumidification, there are many challenges here that we need to continue to research and improve.

Author Contributions: Resources, S.H. and W.C.; investigation, W.C.; writing-original draft preparation, S.H.; writing-review and editing, S.H.; supervision, X.Z.; funding acquisition, W.Y. All authors have read and agreed to the published version of the manuscript.

Funding: This research was funded by the National Key R\&D Program of China: Low Energy Dew Point Cooling for Computing Data Centres [2016YFE0133300]; EUROPEAN COMMISSION: Horizon 2020-Research and Innovation Framework Programme: Low Energy Dew Point Cooling for Computing Data Centres [734340-DEW-COOL-4-CDC-MSCA-RIS. and "The APC was funded by Hunan Provincial College Innovation and Entrepreneurship Education Base (REANG ECO-ENERGY Innovation and Entrepreneurship Education Base) Construction Fund".

Conflicts of Interest: The authors declare no conflict of interest.

\section{References}

1. Qu, M.; Abdelaziz, O.; Gao, Z.M.; Yin, H.X. Isothermal membrane-based air dehumidification: A comprehensive review. Renew. Sustain. Energy Rev. 2018, 82, 4060-4069. [CrossRef]

2. Daou, K.; Wang, R.Z.; Xia, Z.Z. Desiccant cooling air conditioning: A review. Renew. Sustain. Energy Rev. 2006, 10, 55-77. [CrossRef]

3. Vakiloroaya, V.; Samali, B.; Fakhar, A.; Pishghadam, K. A review of different strategies for HVAC energy saving. Energy Convers. Manag. 2014, 77, 738-754. [CrossRef]

4. Zhang, F.; Yin, Y.; Zhang, X. Performance analysis of a novel liquid desiccant evaporative cooling fresh air conditioning system with solution recirculation. Build. Environ. 2017, 117, 218-229. [CrossRef]

5. Li, Z.; Michiyuki, S.; Takeshi, F. Experimental study on heat and mass transfer characteristics for a desiccant-coated fin-tube heat exchanger. Int. J. Heat Mass Transf. 2015, 89, 641-651. [CrossRef]

6. Chatterjee, A.; Derby, M.M.; Peles, Y.; Jensen, M.K. Enhancement of condensation heat transfer with patterned surfaces. Int. J. Heat Mass Transf. 2014, 71, 675-681. [CrossRef]

7. She, X.H.; Cong, L.; Nie, B.J.; Leng, G.H.; Peng, H.; Chen, Y.; Zhang, X.S.; Wen, T.; Yang, H.X.; Luo, Y.M. Energy-efficient and -economic technologies for air conditioning with vapor compression refrigeration: A comprehensive review. Appl. Energy 2018, 232, 157-186. [CrossRef]

8. Maher, S. Review of humidity control technologies in buildings. J. Build. Eng. 2018, 19, 539-551.

9. Mosavi, A.; Mehdizadeh, H.; Abbasian-Naghneh, S.; Kalbasi, R.; Cheraghian, G. Incorporation of horizontal fins into a pcm-based heat sink to enhance the safe operation time: Applicable in electronic device cooling. Appl. Sci. 2020, 10, 6308. [CrossRef]

10. Rostami, S.; Aghakhani, S.; Pordanjani, A.H.; Afrand, M.; Shadloo, M.S. A review on the control parameters of natural convection in different shaped cavities with and without nanofluid. Processes 2020, 8, 1011. [CrossRef]

11. Huang, J.; Liu, M.; Jin, T. A comprehensive empirical correlation for finned heat exchangers with parallel plates working in oscillating flow. Appl. Sci. 2017, 7, 117. [CrossRef]

12. Liang, C.; Tong, X.; Lei, T.; Li, Z.; Wu, G. Optimal design of an air-to-air heat exchanger with cross-corrugated triangular ducts by using a particle swarm optimization algorithm. Appl. Sci. 2017, 7, 554. [CrossRef]

13. Ganesan, P.; Vanaki, S.M.; Thoo, K.K.; Chin, W.M. Air-side heat transfer characteristics of hydrophobic and super-hydrophobic fin surfaces in heat exchangers: A review. Int. Commun. Heat Mass 2016, 74, 27-35. [CrossRef]

14. Caprì, A.; Frazzica, A.; Calabrese, L. Recent developments in coating technologies for adsorption heat pumps: A review. Coatings 2020, 10, 855. [CrossRef]

15. Sultan, M.; El-Sharkawy, I.I.; Miyazaki, T.; Saha, B.B.; Koyama, S. An overview of solid desiccant dehumidification and air conditioning systems. Renew. Sustain. Energy Rev. 2015, 46, 16-29. [CrossRef]

16. Ling, J.; Kuwabara, O.; Hwang, Y.; Radermacher, R. Experimental evaluation and performance enhancement prediction of desiccant assisted separate sensible and latent cooling air-conditioning system. Int. J. Refrig. 2011, 34, 946-957. [CrossRef]

17. Qadar, G.C.; Muzaffar, A.; Nadeem, A.S.; Syed, I.H.G.; Shahab, K. Integration of solar assisted solid desiccant cooling system with efficient evaporative cooling technique for separate load handling. Appl. Therm. Eng. 2018, 140, 696-706. [CrossRef]

18. Aziz, A.A.; Sumiyoshi, D.; Akashi, Y. Low cost humidity controlled air-conditioning system for building energy savings in tropical climate. J. Build. Eng. 2017, 11, 9-16. [CrossRef] 
19. Vivekh, P.; Kumja, M.; Bui, D.T.; Chua, K. Recent developments in solid desiccant coated heat exchangers-A review. Appl. Energy 2018, 229, 778-803. [CrossRef]

20. Tu, Y.D.; Wang, R.Z.; Hua, L.J.; Ge, T.S.; Cao, B.Y. Desiccant-coated water-sorbing heat exchanger: Weakly-coupled heat and mass transfer. Int. J. Heat Mass Transf. 2017, 113, 22-31. [CrossRef]

21. Shang, Y.; Zhang, D.; Guo, L. Cucl-intermediated construction of short-range-ordered $\mathrm{Cu}_{2} \mathrm{O}$ mesoporous spheres with excellent adsorption performance. J. Mater. Chem. 2011, 22, 856-861. [CrossRef]

22. Oh, S.J.; Ng, K.C.; Thu, K.; Ja, M.K.; Islam, M.R.; Chun, W.; Chua, K.J.E. Studying the performance of a dehumidifier with adsorbent coated heat exchangers for tropical climate operations. Sci. Technol. Built Energy 2017, 23, 127-135. [CrossRef]

23. Dhar, P.L.; Singh, S.K. Studies on solid desiccant based hybrid air-conditioning systems. Appl. Therm. Eng. 2001, 21, 119-134. [CrossRef]

24. Erta, H.; Orhan, B.; Lmaz, T.; Hepba, A. Experimental investigation of a novel desiccant cooling system. Energy Build. 2010, 42, 2049-2060.

25. Saeed, A.; Al-Alili, A. A review on desiccant coated heat exchangers. Sci. Technol. Built Energy 2016, 23, 136-150. [CrossRef]

26. Akram, E.; Ge, T.S.; Wang, R.Z. Water adsorption on the coated aluminum sheets by composite materials $(\mathrm{LiCl}+\mathrm{LiBr}) /$ silica gel Energy 2018, 160, 64-71.

27. Zhao, Y.; Ge, T.S.; Dai, Y.J.; Wang, R.Z. Experimental investigation on a desiccant dehumidification unit using fin-tube heat exchanger with silica gel coating. Appl. Therm. Eng. 2014, 63, 52-58. [CrossRef]

28. La, D.; Dai, Y.J.; Li, Y.; Wang, R.Z.; Ge, T.S. Technical development of rotary desiccant dehumidification and air conditioning: A review. Renew. Sustain. Energy Rev. 2010, 14, 130-147. [CrossRef]

29. Zheng, X.; Ge, T.S.; Jiang, Y.; Wang, R.Z. Experimental study on silica gel-licl composite desiccants for desiccant coated heat exchanger. Int. J. Refrig. 2015, 51, 24-32. [CrossRef]

30. Oh, S.J.; Ng, K.C.; Chun, W.; Chua, K. Evaluation of a dehumidifier with adsorbent coated heat exchangers for tropical climate operations. Energy 2017, 137, 441-448. [CrossRef]

31. Bongs, C.; Morgenstern, A.; Lukito, Y.; Henning, H.M. Advanced performance of an open desiccant cycle with internal evaporative cooling. Sol. Energy 2014, 104, 103-114. [CrossRef]

32. Ge, T.S.; Dai, Y.J.; Wang, R.Z.; Peng, Z.Z. Experimental comparison and analysis on silica gel and polymer coated fin-tube heat exchangers. Energy 2010, 35, 2893-2900. [CrossRef]

33. Tu, Y.D.; Wang, R.Z.; Ge, T.S. Moisture uptake dynamics on desiccant-coated, water-sorbing heat exchanger. Int. J. Therm. Sci. 2018, 126, 13-22. [CrossRef]

34. Zheng, X.; Wang, R.Z.; Ge, T.S.; Hu, L.M. Performance study of sapo-34 and fapo-34 desiccants for desiccant coated heat exchanger systems. Energy 2015, 93, 88-94. [CrossRef]

35. Aristov, Y.I. Challenging offers of material science for adsorption heat transformation: A review. Appl. Therm. Eng. 2013, 50, 1610-1618. [CrossRef]

36. Bidyut, B.S.; Anutosh, C.; Shigeru, K.; Yu, I.A. A new generation cooling device employing $\mathrm{CaCl}_{2}$-in-silica gel-water system. Int. J. Heat Mass Transf. 2009, 52, 516-524.

37. Aristov, Y.I.; Restuccia, G.; Tokarev, M.M.; Buerger, H.D.; Freni, A. Selective water sorbents for multiple applications. 11. CaCl 2 confined to expanded vermiculite. React. Kinet. Catal. Lett. 2000, 71, 377-384. [CrossRef]

38. Jia, C.X.; Dai, Y.J.; Wu, J.Y.; Wang, R.Z. Experimental comparison of two honeycombed desiccant wheels fabricated with silica gel and composite desiccant material. Energy Convers. Manag. 2006, 47, 2523-2534. [CrossRef]

39. Jia, C.X.; Dai, Y.J.; Wu, J.Y.; Wang, R.Z. Use of compound desiccant to develop high performance desiccant cooling system. Int. J. Refrig. 2007, 30, 345-353. [CrossRef]

40. Ge, T.S.; Ziegler, F.; Wang, R.Z. A mathematical model for predicting the performance of a compound desiccant wheel (a model of compound desiccant wheel). Appl. Therm. Eng. 2010, 30, 1005-1015. [CrossRef]

41. Zheng, X.; Ge, T.S.; Wang, R.Z. Recent progress on desiccant materials for solid desiccant cooling systems. Energy 2014, 74, 280-294. [CrossRef]

42. Zheng, X.; Wang, R.Z.; Ge, T.S. Experimental study and performance predication of carbon based composite desiccants for desiccant coated heat exchangers. Int. J. Refrig. 2016, 72, 124-131. [CrossRef]

43. Hu, L.M.; Ge, T.S.; Jiang, Y.; Wang, R.Z. Performance study on composite desiccant material coated fin-tube heat exchangers. Int. J. Heat Mass Transf. 2015, 90, 109-120. [CrossRef]

44. Gordeeva, L.G.; Grekova, A.D.; Krieger, T.A.; Aristov, Y.I. Adsorption properties of composite materials $(\mathrm{LiCl}+\mathrm{LiBr}) /$ silica. Micropor. Mesopor. Mater. 2009, 126, 262-267. [CrossRef]

45. Ge, T.S.; Zhang, J.Y.; Dai, Y.J.; Wang, R.Z. Experimental study on performance of silica gel and potassium formate composite desiccant coated heat exchanger. Energy 2017, 141, 149-158. [CrossRef]

46. Jagirdar, M.; Lee, P.S. Mathematical modeling and performance evaluation of a desiccant coated fin-tube heat exchanger. Appl. Energy 2018, 212, 401-415. [CrossRef]

47. Andres, S.V.; Sun, X.Y.; Ge, T.S.; Dai, Y.J.; Wang, R.Z. Experimental investigation on performance of a novel composite desiccant coated heat exchanger in summer and winter seasons. Energy 2019, 166, 506-518.

48. Zheng, X.; Chen, K.; Lin, Z. Synthesis and characterization of alginate-silica gel composites for adsorption dehumidification. Ind. Eng. Chem. Res. 2020, 59, 5760-5767. [CrossRef] 
49. Entezari, M.; Wang, R. Super atmospheric water harvesting hydrogel with alginate chains modified with binary salts. ACS Mater. Lett. 2020, 2, 471-477. [CrossRef]

50. Ge, T.S.; Cao, W.; Pan, X.; Dai, Y.J.; Wang, R.Z. Experimental investigation on performance of desiccant coated heat exchanger and sensible heat exchanger operating in series. Int. J. Refrig. 2017, 83, 88-98. [CrossRef]

51. Tomohiro, H.; Mao, Y.; Naoki, N.; Chaobin, D.; Eiji, H. Gravimetric method for sorption performance measurement of desiccant wheel and desiccant coated heat exchanger. Appl. Therm. Eng. 2018, 144, 639-646.

52. Sun, X.Y.; Dai, Y.J.; Ge, T.S.; Zhao, Y.; Wang, R.Z. Experimental and comparison study on heat and moisture transfer characteristics of desiccant coated heat exchanger with variable structure sizes. Appl. Therm. Eng. 2018, 38, 1822-1827. [CrossRef]

53. Chai, S.W.; Sun, X.Y.; Zhao, Y.; Dai, Y.J. Experimental investigation on a fresh air dehumidification system using heat pump with desiccant coated heat exchanger. Energy 2019, 171, 306-314. [CrossRef]

54. Ge, T.S.; Dai, Y.J.; Wang, R.Z.; Li, Y. Feasible study of a self-cooled solid desiccant cooling system based on desiccant coated heat exchanger. Appl. Therm. Eng. 2013, 58, 281-290. [CrossRef]

55. Turkan, U.E.; Ali, G.; Hannes, F.; Alexander, M.; Constanze, B. Performance evaluation of a desiccant coated heat exchanger with two different desiccant materials. Appl. Therm. Eng. 2018, 143, 701-710.

56. Kumar, A.; Yadav, A. Experimental investigation of solar driven desiccant air conditioning system based on silica gel coated heat exchanger. Int. J. Refrig. 2016, 69, 51-63. [CrossRef]

57. Sun, X.Y.; Dai, Y.J.; Ge, T.S.; Zhao, Y.; Wang, R.Z. Comparison of performance characteristics of desiccant coated air-water heat exchanger with conventional air-water heat exchanger-experimental and analytical investigation. Energy 2017, 137, 399-411. [CrossRef]

58. Ge, T.S.; Dai, Y.J.; Wang, R.Z. Performance study of desiccant coated heat exchanger air conditioning system in winter. Energy Convers. Manag. 2016, 123, 559-568. [CrossRef]

59. Ma, X.; Ding, G.; Zhang, Y.; Wang, K. Airside heat transfer and friction characteristics for enhanced fin-and-tube heat exchanger with hydrophilic coating under wet conditions. Int. J. Refrig. 2007, 30, 1153-1167. [CrossRef]

60. Luo, Y.; Yang, H.; Lu, L. Dynamic and microscopic simulation of the counter-current flow in a liquid desiccant dehumidifier. Appl. Energy 2014, 136, 1018-1025. [CrossRef]

61. Guo, L.; Tang, G.H. Dropwise condensation on bioinspired hydrophilic-slippery surface. RSC Adv. 2018, 8, 39341-39351. [CrossRef]

62. Sheng, Q.; Sun, J.; Wang, Q.; Wang, W.; Wang, H.S. On the onset of surface condensation: Formation and transition mechanisms of condensation mode. Sci. Rep. 2016, 6, 1-9. [CrossRef]

63. Zhao, H.; Beysens, D. From droplet growth to film growth on a heterogeneous surface: Condensation associated with a wettability gradient. Langmuir 1995, 11, 627-634. [CrossRef]

64. Patankar, N.A. Supernucleating surfaces for nucleate boiling and dropwise condensation heat transfer. Soft Matter 2010, 6, 1613-1620. [CrossRef]

65. Ishii, D.; Yabu, H.; Shimomura, M. Novel biomimetic surface based on a self-organized metal-polymer hybrid structure. Chem. Mater. 2009, 21, 1799-1801. [CrossRef]

66. Thickett, S.C.; Neto, C.; Harris, A.T. Biomimetic surface coatings for atmospheric water capture prepared by dewetting of polymer films. Adv. Mater. 2011, 23, 3718-3722. [CrossRef]

67. Young, T. An essay on the cohesion of fluids. Phil. Trans. Roy. Soc. Lond. 1805, 95, 65-87.

68. Wenzel, R.N. Resistance of solid surfaces to wetting by water. Trans. Faraday Soc. 1936, 28, 988-994. [CrossRef]

69. Cassie, A.B.D.; Baxter, S. Wettability of porous surfaces. Trans. Faraday Soc. 1944, 40, 546-551. [CrossRef]

70. Suzuki, S.; Ueno, K. Apparent contact angle calculated from a water repellent model with pinning effect. Langmuir 2017, 33, 138-143. [CrossRef]

71. Mondal, B.; Eain, M.M.G.; Xu, Q.F.; Egan, V.M.; Punch, J.; Lyons, A.M. Design and fabrication of a hybrid superhydrophobichydrophilic surface that exhibits stable dropwise condensation. ACS Appl. Mater. Interfaces 2015, 7, 23575-23588. [CrossRef]

72. Ju, J.; Yao, X.; Yang, S.; Wang, L.; Jiang, L. Cactus stem inspired cone-arrayed surfaces for efficient fog collection. Adv. Funct. Mater. 2014, 24, 6933-6938. [CrossRef]

73. Hu, H.W.; Tang, G.H.; Niu, D. Experimental investigation of condensation heat transfer on hybrid wettability finned tube with large amount of noncondensable gas. Int. J. Heat Mass Transf. 2015, 85, 513-523. [CrossRef]

74. Mahapatra, P.S.; Ghosh, A.; Ganguly, R.; Megaridis, C.M. Key design and operating parameters for enhancing dropwise condensation through wettability patterning. Int. J. Heat Mass Transf. 2016, 92, 877-883. [CrossRef]

75. Ghosh, A.; Beaini, S.; Zhang, B.J.; Ganguly, R.; Megaridis, C.M. Enhancing dropwise condensation through bioinspired wettability patterning. Langmuir 2014, 30, 13103-13115. [CrossRef]

76. Derby, M.M.; Chatterjee, A.; Peles, Y.; Jensen, M.K. Flow condensation heat transfer enhancement in a mini-channel with hydrophobic and hydrophilic patterns. Int. J. Heat Mass Transf. 2014, 68, 151-160. [CrossRef]

77. Alwazzan, M.; Egab, K.; Peng, B.; Khan, J.; Chen, L. Condensation on hybrid-patterned copper tubes (i): Characterization of condensation heat transfer. Int. J. Heat Mass Transf. 2017, 112, 991-1004. [CrossRef]

78. Yin, K.; Du, H.; Dong, X.; Wang, C.; Duan, J.; He, J. A simple way to achieve bioinspired hybrid wettability surface with micro/nanopatterns for efficient fog collection. Nanoscale 2017, 9, 14620-14626. [CrossRef] [PubMed] 
79. Cao, M.; Xiao, J.; Yu, C.; Li, K.; Jiang, L. Hydrophobic/hydrophilic cooperative janus system for enhancement of fog collection. Small 2015, 11, 4379-4384. [CrossRef] [PubMed]

80. Li, J.S.; Ueda, E.; Nallapaneni, A.; Li, L.X.; Levkin, P.A. Printable superhydrophilic-superhydrophobic micropatterns based on supported lipid layers. Langmuir ACS J. Surf. Colloids 2012, 28, 8286-8291. [CrossRef]

81. Garrod, R.P.; Harris, L.G.; Schofield, W.C.E.; Mcgettrick, J.; Ward, L.J.; Teare, D.O.H. Mimicking a stenocara beetles back for microcondensation using plasmachemical patterned superhydrophobic/superhydrophilic surfaces. Langmuir 2007, 23, 689-693. [CrossRef]

82. Hou, Y.; Yu, M.; Chen, X.; Wang, Z.; Yao, S. Recurrent filmwise and dropwise condensation on a beetle mimetic surface. ACS Nano 2015, 9, 71-81. [CrossRef]

83. Lei, Z.; Berg, M.C.; Cebeci, F.C.; Kim, Y.; Milwid, J.M.; Rubner, M.F.; Cohen, R.E. Patterned superhydrophobic surfaces: Toward a synthetic mimic of the namibdesert beetle. Nano Lett. 2006, 6, 1213-1217.

84. Zhang, L.; Wu, J.; Hedhili, M.; Yang, X.; Wang, P. Inkjet printing for direct micropatterning of a superhydrophobic surface: Toward biomimetic fog harvesting surfaces. J. Mater. Chem. A 2015, 3, 2844-2852. [CrossRef]

85. Zhuang, D.; Ding, G.; Hu, H.; Fujino, H.; Inoue, S. Condensing droplet behaviors on fin surface under dehumidifyingcondition: Part I: Numerical model. Appl. Therm. Eng. 2016, 105, 336-344. [CrossRef]

86. Ma, X.; Ding, G.; Zhang, Y.; Wang, K. Effects of hydrophilic coating on air side heat transfer and friction characteristics of wavy fin and tube heat exchangers under dehumidifying conditions. Energy Convers. Manag. 2007, 48, 2525-2532. [CrossRef]

87. Yang, K.S.; Lin, K.H.; Tu, C.W.; He, Y.Z.; Wang, C.C. Experimental investigation of moist air condensation on hydrophilic, hydrophobic, superhydrophilic, and hybrid hydrophobic-hydrophilic surfaces. Int. J. Heat Mass Transf. 2017, 115, $1032-1041$. [CrossRef]

88. Wang, C.C.; Chang, C.T. Heat and mass transfer for plate fin-and-tube heat exchangers, with and without hydrophilic coating. Int. J. Heat Mass Transf. 1998, 41, 3109-3120. [CrossRef]

89. Wang, C.C.; Lee, W.S.; Sheu, W.J.; Chang, Y.J. A comparison of the airside performance of the fin-and-tube heat exchangers in wet conditions; with and without hydrophilic coating. Appl. Therm. Eng. 2002, 22, 267-278. [CrossRef]

90. Kim, K.; Lee, K.S. Characteristics and performance evaluation of surface-treated louvered-fin heat exchangers under frosting and wet conditions. Int. J. Heat Mass Transf. 2012, 55, 6676-6681. [CrossRef] 